\title{
Flatté, Rowe, Sartori, Shastri, and Wang to chair 2020 MRS Fall Meeting
}

mrs.org/fall2020

$\mathrm{T}^{\mathrm{s}}$ he Meting Chairs for the 2020 Materials Research Society (MRS) Fall Meeting are Michael E. Flatté (The University of Iowa, USA), Michael P. Rowe (Toyota Research Institute of North America, USA), Sabrina Sartori (University of Oslo, Norway), Prasad Shastri (University of Freiburg, Germany), and Chongmin Wang (Pacific Northwest National Laboratory, USA). The Meeting will be held November 29December 4, 2020, in Boston, Mass.

Michael E. Flatté is a professor in the Department of Physics and Astronomy

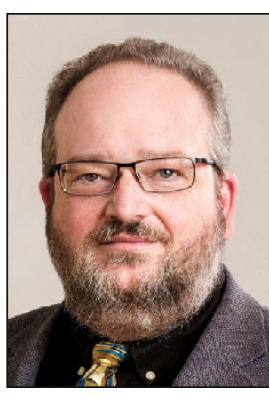

at The University of Iowa (UI). His research interests include optical and electrical control of spin dynamics in materials, novel spintronic devices, quantum sensors, and solid-state realizations of quantum computation. He received an $\mathrm{AB}$ degree in physics from Harvard University in 1988 and $\mathrm{PhD}$ degree in physics from the University of California, Santa Barbara (UCSB) in 1992. After postdoctoral work at the Institute for Theoretical Physics at UCSB and in the Division of Applied Sciences at Harvard University, he joined the faculty at UI in 1995 . He was director of UI's Optical Science and Technology Center from 2010 to 2017. Flatté has more than 200 publications and 10 patents. He is a Fellow of the American Association for the Advancement of Science and of the American Physical Society (APS), a member of MRS, The Optical Society, and the American Vacuum Society, and was chair of the Division of Materials Physics of APS from 2016 to 2017. Flatté also has an adjunct appointment as professor in the Department of Applied Physics at Eindhoven University of Technology in The Netherlands.
Michael P. Rowe is a principal scientist at the Toyota Research Institute

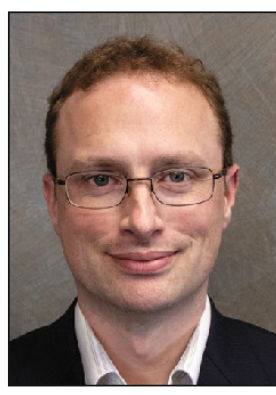

of North America, having joined Toyota's North American Research and Development operations in 2008. He received his $\mathrm{BA}$ degree in chemistry from Knox College and MS and $\mathrm{PhD}$ degrees in chemistry from the University of Michigan, continuing with his postdoctoral research also at the University of Michigan. His work focuses on using bottom-up chemical approaches to control nanomaterial properties so that original futuristic ideas can become real-world applications. His current research programs span a broad range of fields, including lightweight steel composites to reduce environmental affects through improved vehicle fuel economy, and artificial muscle, soft robotics to improve the quality of life for elderly and disabled people. Rowe has received four Toyota Research Division Awards for his research accomplishments. He and his teams have generated more than 40 patents, in addition to numerous conference presentations and peer-reviewed publications.

Sabrina Sartori is an associate professor and leader of the Energy Systems

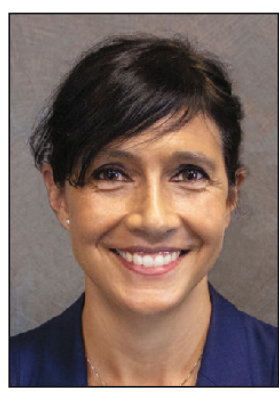

section in the Department of Technology Systems at the University of Oslo. Her research interests include materials for energy storage and conversion and their characterization via in situ and operando synchrotron and neutron radiation experiments. She earned her MSc degree in chemistry from the University of Padova and $\mathrm{PhD}$ degree in materials science and engineering from the University of Bologna. She has held research positions at the University of Padova and the Institute for Energy Technology in Norway, before joining the University of Oslo in 2013. Sartori serves on the MRS Bulletin Energy Quarterly Board, served on the MRS Board of Directors (2015-2017), and currently serves as an expert and leader on several national and international committees, boards, and initiatives.

Prasad Shastri is a professor at the University of Freiburg, Germany, where

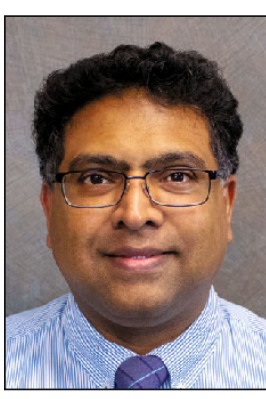

he holds the Hermann Staudinger Chair for Biofunctional Macromolecular Chemistry and the BIOSS Professorship of Cell Signaling Environments. He is also

the director of the Institute for Macromolecular Chemistry and one of the core faculty at the BIOSS Center for Biological Signaling Studies, which is one of the national clusters of Excellence in Germany. He received his $\mathrm{PhD}$ degree in chemistry from Rensselaer Polytechnic Institute in 1995, and carried out postdoctoral work with Robert Langer at the Massachusetts Institute of Technology. Shastri has published more than 120 peer-reviewed papers and has authored several proceedings articles, extended abstracts, and book chapters. He has also authored more than 50 issued and pending patents in materials science, regenerative medicine, and tumor biology. His laboratory is active in the development of biomaterials for controlling cellular microenvironments, in vivo engineering of tissue, intracellular delivery, cancer therapeutics, cancer biology, 3D-bioprinting, bioink development, and functional imaging. 


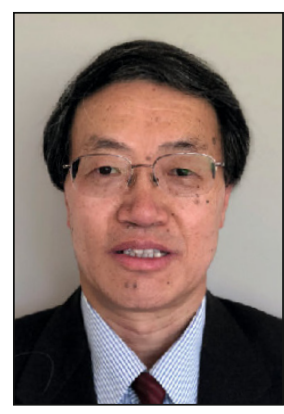

Chongmin Wang is a Laboratory Fellow at Pacific Northwest National Laboratory (PNNL), and his research interests include $\mathrm{S} / \mathrm{TEM}$ imaging and spectroscopy and their application to materials characterization, especially in situ and operando S/TEM techniques for energy materials. He received his BSc and MSc degrees in physics from Lanzhou University in China and a $\mathrm{PhD}$ degree in materials science and engineering from the University of Leeds, UK. He has received the 2016 MRS Innovation in Materials Characterization Award, the 2017 PNNL Laboratory Director's Award for Exceptional Scientific Achievement, the 2016 Journal of Materials Research
(JMR) Paper of the Year Award, the R\&D 100 Award, the Rowland Snow Award from The American Ceramic Society, the Japanese Outstanding Invention Award from the Ministry of Science and Education of Japan, and the PNNL Exceptional Contribution Award. Wang has published 370 journal papers and several book chapters and has delivered 70 invited talks. He currently serves as a principal editor of $J M R$ and is a Fellow of MRS.

\section{Become an $\mathbf{M}|\mathbf{R}| \mathbf{S}^{\circledR}$ \\ Congressional Science and Engineering Fellow}

Decisions made by Congress, regulatory agencies and local government have profound effects on the way in which science is conducted. By keeping decision makers well informed on the current affairs of the scientific community, MRS Congressional Science and Engineering Fellows ensure the right choices are being made. Now's your time to make a difference!

The Materials Research Society offers materials scientists two exciting opportunities to participate in, and contribute to, the federal policymaking process, while learning firsthand about the intersection of science and policy.

During your year as a Fellow you will:

- contribute widely to the effective use of materials science knowledge in government

- broaden awareness about the value of scientist- and engineer-government interaction among society members and within government

- have significant freedom to follow specific topics and issues that interest you

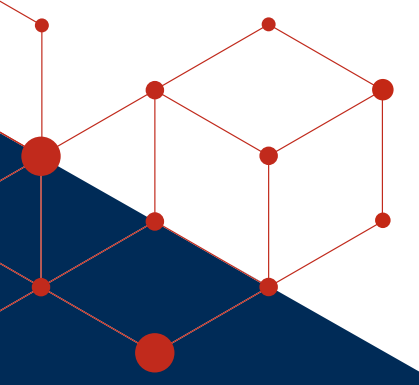

To learn more about the

MRS Congressional Science

and Engineering Fellowship

Program and how you can apply, visit

mrs.org/congressional-fellows.

Applications for the 2020-2021 MRS Congressional Science and Engineering Fellowship Program are posted on the MRS website.

\section{Deadline for submission is January 3, 2020.}

Help improve the interface between science and legislative decision making.

Advocate for policies that will facilitate the discoveries of the future.

Play a crucial role as you educate the public about the benefits of science.

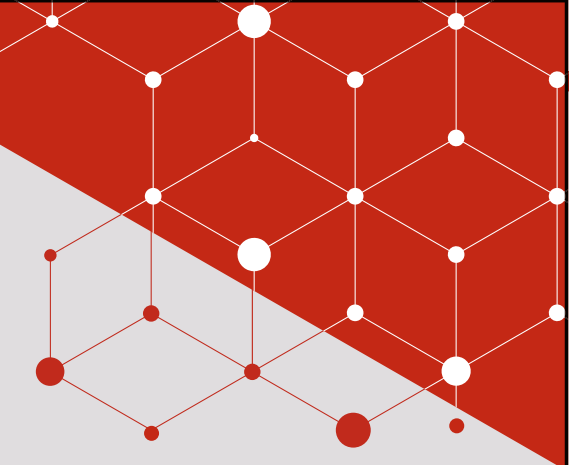

The MRS Congressional Science and Engineering Fellowship Program is an invaluable experience, but don't just take our word for it. This past Congressional Fellow explains it best!

"Academia taught me how to think, but the MRS Congressional Fellowship taught me how to get things done. Never have I had such leverage, such opportunities to comingle with dignitaries, to structure agreements and broker deals, as I did in that year. I learned how to navigate past armies of secretaries shielding a VIP, enlist military support for a project, take a rough idea and make it law, to fashion an event into a sound bite and then watch it propagate across the news. I learned to take data and present it in such a way that it gravitated, almost of its own accord, all the way up to the Vice President of the United States. These are skills anyone, who is going anywhere, can use."

Merrilea Mayo Founder, Mayo Enterprises, LLC MRS Congressional Fellow 1998-1999 Office of Senator Lieberman 